\title{
Experimental and Numerical Investigation of Blades Slots on Rotating Stall Phenomenon in Centrifugal Blower
}

\author{
Muna S. Kassim*, Fouad A. Saleh, Mohammed A. Kadhum \\ Mechanical Department, College of Engineering, Al-Mustansiriyah University, Iraq
}

Copyright (C) 2015 Horizon Research Publishing All rights reserved.

\begin{abstract}
Experimental and numerical investigations to study the effect of adding slots to the blades on the rotating stall phenomenon and pressure fluctuations in centrifugal blower. The experimental test rig which concludes a centrifugal blower, pressure sensors and measurement instrumentations are design and constructed for the present work. The experimental study has been carried out by measuring the static pressure variation and pressure fluctuation for two cases of impeller (with and without slots). Measuring of static values has been completed at various points prepared on the front-wall of the volute casing along one path for two cases of impeller. Enhancement in pressure distribution adds slots to the blades comparison with cases without slots at values of mass flow rate between non-flow and $0.02254 \mathrm{~kg} / \mathrm{s}$. The pressure fluctuations increase with decrease values of mass flow rates. We concluded also that pressure fluctuations decrease with adding slots to blades. This led to decrease occur of rotating stall phenomenon and increase stability of centrifugal blower. Numerical simulation has been carried out on present centrifugal blower to analyze both flow field and pressure fluctuations by using FLUENT 14 package. The numerical simulation has been completed by solving the continuity and momentum equations with moving reference frame technique inside the blower. The results of numerical simulation give a good agreement with the experimental results.
\end{abstract}

Keywords Rotating Stall, Centrifugal Blower, Impeller and Slots

\section{Introduction}

According to literature review, slots are made at the points of separation so as to attenuate the boundary layer by which boundary layer buildup can be controlled in the centrifugal impeller. These slots had been design in the literature survey in such a way that a jet of fluid effluxes through the converging slot from the pressure side to the suction side. This results in moving the separation region closer to the wall of the impeller, thus reducing the slip as well as flow losses. A host of studies had been undertaken, mostly experimentally, to assess the efficacy of these boundary layer suction slots in the impeller or diffuser of various types of turbo machines.

The useful range of operation of centrifugal systems is limited, by chocking at high mass flows when sonic velocity is reached in some components, and at low mass flows by the onset of three instabilities known as surge, stall and rotating stall. Rotating stall is a two-dimensional, local instability phenomenon in which one more local regions of stagnant flow, so-called stall cells, rotate around the circumference of the blower [1]. Surge is characterized by large amplitude fluctuations of the pressure and unsteady, but circumferentially uniform, annulus-averaged mass flow [2]. This is essentially one-dimensional instability; it affects the compression system as a whole and results in a limited cycle oscillation in the blower map. These instabilities can lead to severe damage of the machine because of large mechanical and thermal loads in the blading, and consequently restrict its performance and efficiency [3].

A great deal of work has been carried out on flow behavior investigation in various parts of the turbo machines. Sivagnansundaram et al. [4] investigated the enhancement of compressor map width using a shroud bleed slot with various slot geometries. Three different slot geometries were obtained by modifying the original slot width. Three-dimensional steady-state CFD simulations were performed for a single passage of a turbocharger centrifugal compressor stage to investigate the enhancement of the compressor map width. He concluded that increasing the slot width has considerable influence on the compressor performance in terms of moving the surge point to lower flow rate. In this analysis the wider slot width $(4 \mathrm{~mm})$ reduced the surge flow by about $15 \%$ compared to the baseline slot (3mm). Xiao et al. [5] studied the effect of circumferential grooves casing treatment on tip leakage flow and loss in a transonic mixed-flow compressor. The effect of circumferential grooves casing treatment on the compressor performance, tip leakage flow and loss had been studied. Detailed analysis indicates that the fluid from circumferential grooves is injected into the blade passage near the section surface and re-energizes the leakage flow, which makes mainly contribution to manipulation of the tip 
leakage flow and stall margin improvement. Vasudeva and Yagnesh [6] analyzed the performance enhancement of centrifugal fan by using converging boundary layer suction slots. The analysis shows that the converging suction slots located on the impeller blade about $25 \%$ from the trialing edge, significantly improves the static pressure recovery across the fan. Also it is found that slots provided at a radial distance of about $12 \%$ from the leading and trailing edges marginally improve the static pressure recovery across the fan. Raghunathan and Cooper [7] carried out experiments in short wide-angle diffusers and the control surface was made of slots. The experiments included slots normal to the surface and a combination of slots normal and inclined to the surface. Passive control with inclined slots produced modest improvement in pressure recovery but significant increases in the stall angle. Wursthorn and Schnerr [8] in their work have carried out the control of cavitation by providing a slot near the leading edge of the impeller blade connecting the suction side from the pressure side of the impeller. They carried out 2-D numerical calculations in a rotating frame of reference for an impeller of a radial pump of low specific speed. From these investigations they concluded that, this method was most effective to reduce leading edge suction peaks in the partial capacity operating range.

In this work, experimental and numerical investigations have been applied in order to obtain the pressure fluctuations at the impeller-volute of an industrial centrifugal blower. In this work, we shall discuss the influence of adding slots to the blade of impeller on rotating stall and pressure fluctuation inside the blower. The numerical results have been compared with experimental results obtain from pressure transducer which install on the casing of blower.

\section{Description of the Blower and Experimental Procedures}

The tested machine is a centrifugal blower driven by an AC $600 \mathrm{~W}$ motor which has rotational speed $16000 \mathrm{rpm}$. The unshrouded impellers tested have ten backward-curved blades with an outlet diameter of $110 \mathrm{~mm}$ as shown in Figure (1). The distance between the impeller and the volute tongue is $(12 \mathrm{~mm})$. The widths of the impeller and volute are, $35 \mathrm{~mm}$ and $45 \mathrm{~mm}$ respectively. Table (1) summarizes the main dimensions of its impeller and Figure (2) show two cases of impeller (with and without slots).

The test rig, as shown in the Figure (3) and (4), has been designed and constructed to be appropriate for the purpose of the present and future research. The test rig has been constructs to form an open loop system. The loop consisted of a constant-speed electric blower, a throttle valve, a metering orifice, and piping. The air is collected by a scroll (volute) of circular cross sectional area. The outlet pipe of the blower is connected to an orifice plate air flow meter through $(90 \mathrm{~mm})$ length flexible pipe. The throttle valve (gate valve), fitted on the discharge side of the piping, and allows an accurate and fine control of the mass flow rate.

The static pressure measurements are carried out, by employing a strain gauge pressure transducer. The transducer is designed in order to indicate a differential pressure. The output signals from the transducer are appropriately conditioned and digitized using the data acquisition system. The output signals are also connected to an oscilloscope, to monitor the onset of any perturbation in the flow. This observation will give a continuous display of the variation and measurement problems in order to avoid it.

The measurement for the present study is carried out on the front-wall of the casing. Several measurement taps are arranged on this wall, as shown in Figure (5). The numbers of these taps are twelve and located at every $30^{\circ}$ interval around the front side of the impeller, and at location of $5 \mathrm{~mm}$ from the outlet of the impeller.

Stainless steel tubes of $1 \mathrm{~mm}$ diameter and $20 \mathrm{~mm}$ length are constructed to be used as static pressure taps in this study. The tubes are inserted into the holes (which are drilled on the front side of the blower casing), perpendicularly to the casing wall until the pressure hole of the tubes reaches the surface of the casing wall. The other end of the tube is extended out of the other side of the blower casing. A short plastic tube is employed to connect the transducer of the pressure tap, as shown in Figure (6).

Static pressure measurement at certain location on the casing wall is usually carried out for various mass flow rates. The flow rate is controlled by changing the valve opening at the end of the tube which is connected to volute exit. The impeller rotating speed is constant and limited by the electric motor speed which is measured by tachometer.

The output signal of the transducer, which corresponds to the static pressure fluctuation, is fed to the data logging (acquisition) system. The data logger will digitize the signal at a certain rate per second which is called sampling rate. The number of samples acquired by the data logger and its rate are fully controlled by software which is developed for purpose of this work. The sampled data which correspond to pressure variation with time are stored in certain location in the personal computer memory for further and future processing. The above procedure is repeated for various mass flow rates, number of rotation and locations on casing wall.

Figure (6) shows the total pressure taps, which are constructed by using stainless steel tubes of $1 \mathrm{~mm}$ diameter and $40 \mathrm{~mm}$ length. A side hole, near the closed end is made. The other end of the pressure tube is attached to the plastic tube which in-turn is connected to the pressure transducer or manometer.

Table 1. Main Characteristics of the Tested Impeller

\begin{tabular}{|c|c|}
\hline Impeller exit diameter & $\mathbf{D}=\mathbf{1 1 0} \mathbf{~ m m}$ \\
\hline Impeller inlet diameter & $\mathrm{d}=28 \mathrm{~mm}$ \\
\hline Number of impeller blade & $\mathrm{Z}=10$ \\
\hline Maximum rotational speed & $16000 \mathrm{rpm}$ \\
\hline Inlet blade angle & $\beta_{1}=54^{\circ}$ from tangential direction. \\
\hline Outlet blade angle & $\beta_{2}=42^{\circ}$ from tangential direction. \\
\hline Blade thickness & $3 \mathrm{~mm}$ \\
\hline
\end{tabular}




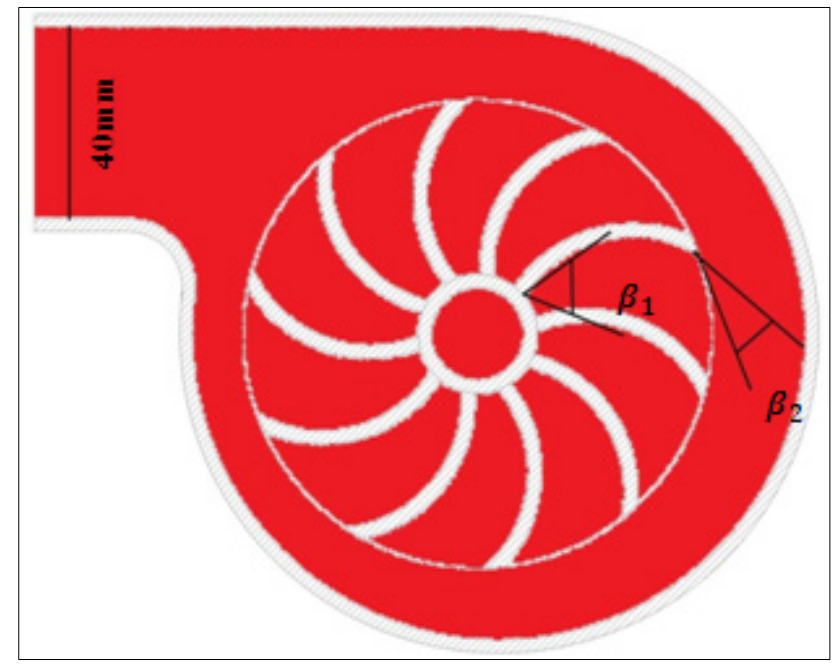

Figure 1. Impeller View and Cross-Sectional View of the Centrifugal Blower.

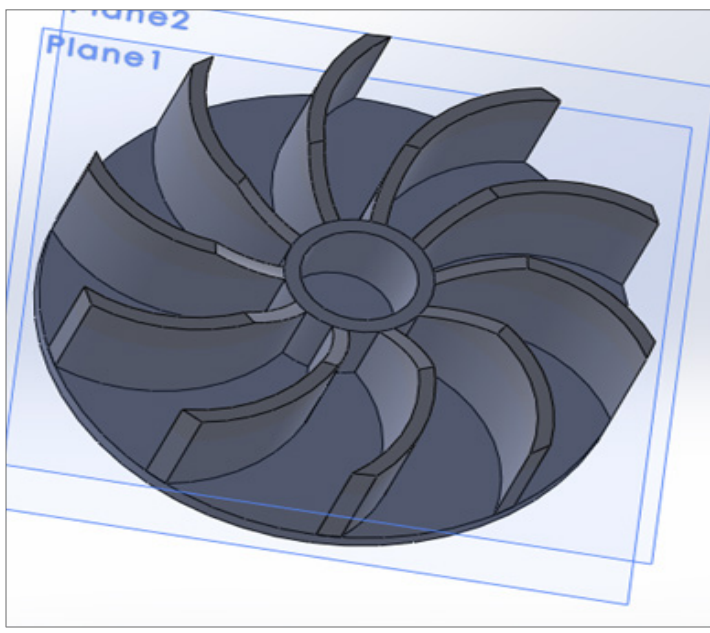

(a) Without slots

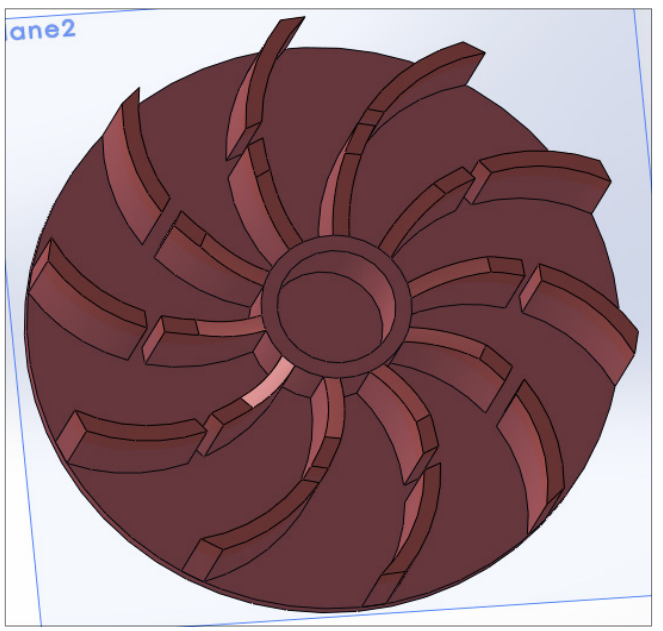

(b) With slots

Figure 2. Impeller Shape

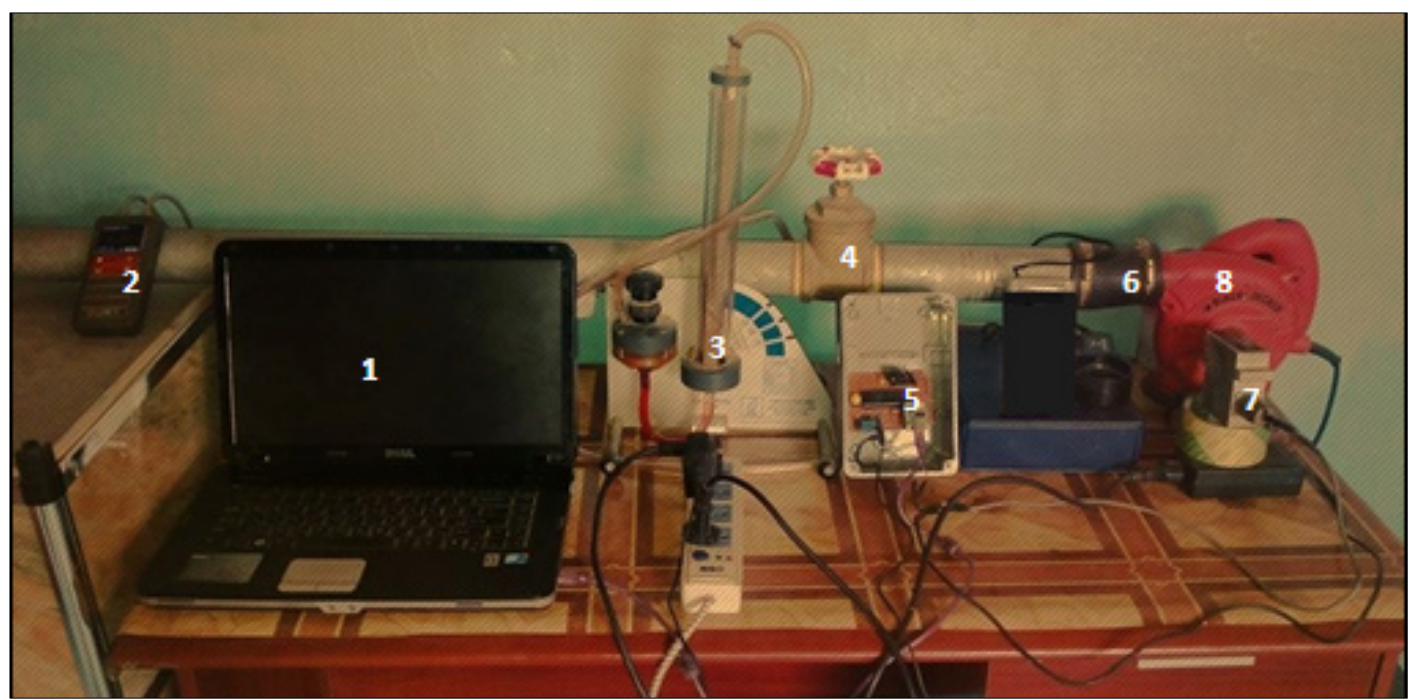

1-. Personal computer 2- Digital manometer 3-U-Tube manometer

5- Interface board 6- Flexible pipe

7- Pressure transducer

4- Valve

8- Centrifugal blower

Figure 3. Experimental Test Rig 


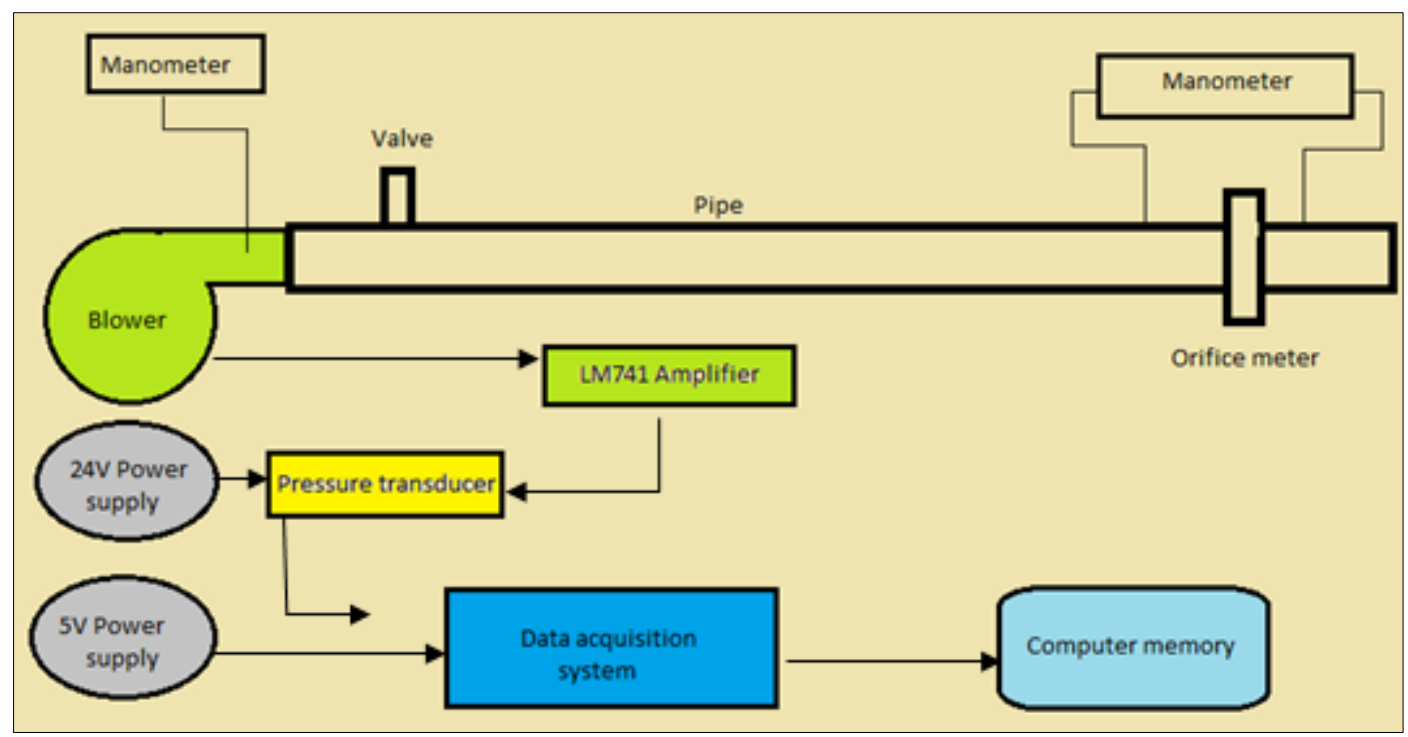

Figure 4. Schematic Diagram for Test Rig

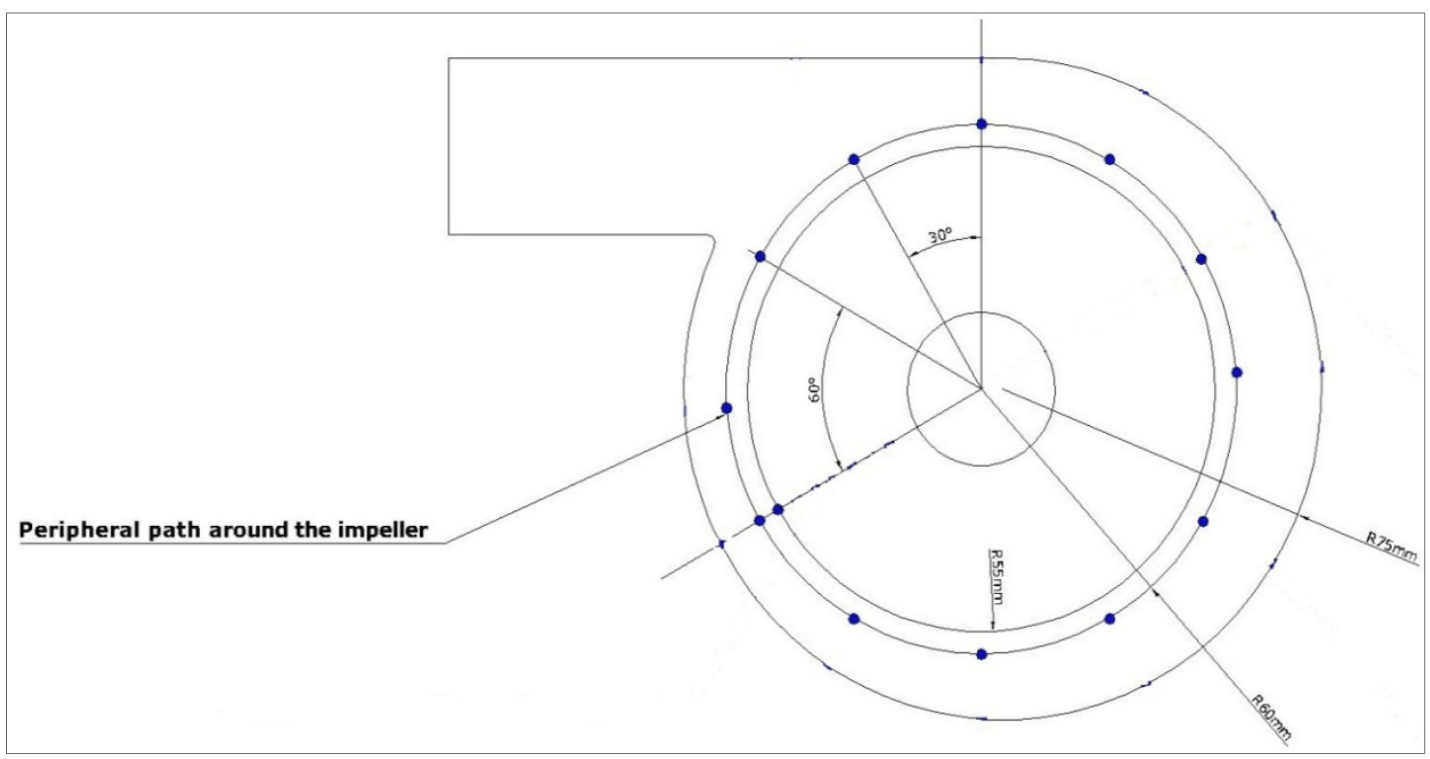

Figure 5. : Locations of Measuring Points

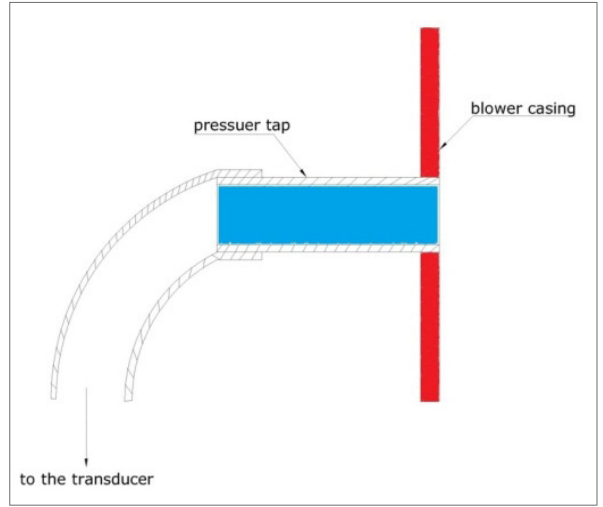

Static Pressure Tap

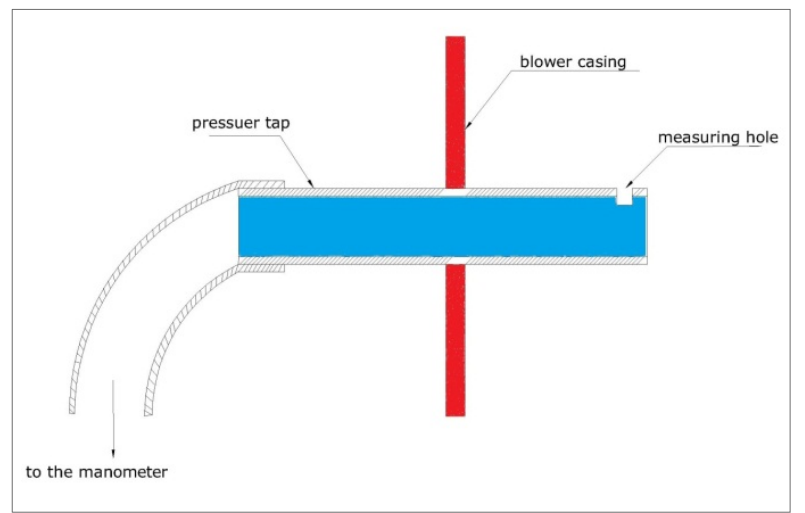

(b) Total Pressure Tap

Figure 6. Static and Total Pressures Tap Arrangement 


\section{Slots Configuration}

Slots are made at the certain point to attenuate the boundary layer by which boundary layer buildup can be controlled in the centrifugal impeller. These slots have been designed in the present work in such a way that a jet of fluid effluxes through the converging slot from the pressure to the suction side.

The slots made in the present work at each blade beginning at radius $34 \mathrm{~mm}$ from impeller inlet and ended at radius $37 \mathrm{~mm}$, therefore the width of each slot $3 \mathrm{~mm}$. Figure (7) shows the schematic diagram for the slot which it made on the impeller blades.

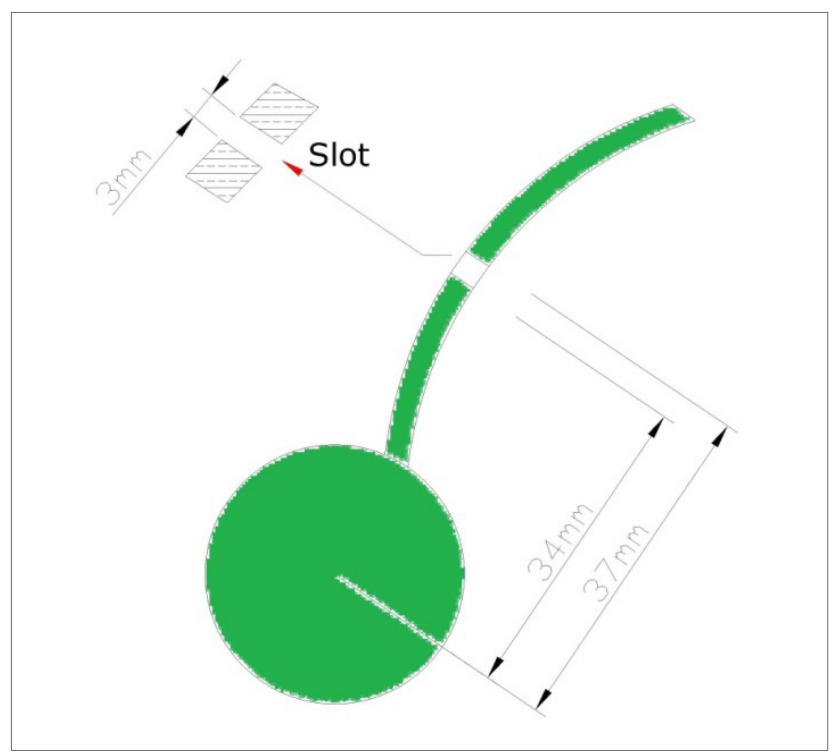

Figure 7. Schematic Diagram for Slot of Impeller.

\section{Numerical Simulation}

In parallel with the measurements, numerical simulations of the unsteady flow in the centrifugal blower described above were carried out. In order to verify the capabilities of the numerical model to describe the flow features inside the blower, a three-dimensional numerical simulation of the unsteady flow has been carried out. All the calculations have been performed with commercial software package FLUENT 14. This code uses the finite volume method and Navier-Stokes equations.

The conservation equation for continuity and momentum equations can be written as follows [9]:

- Continuity equation

$$
\frac{\partial \bar{u}}{\partial x}+\frac{\partial \bar{v}}{\partial y}+\frac{\partial \bar{w}}{\partial z}=0
$$

- Momentum equation in $\mathrm{x}$-direction

$\left(\bar{u} \frac{\partial \bar{u}}{\partial x}+\bar{v} \frac{\partial \bar{u}}{\partial y}+\bar{w} \frac{\partial \bar{u}}{\partial z}\right)=-\frac{1}{\rho} \frac{\partial P}{\partial x}+v \nabla^{2} \bar{u}+\left(-\frac{\partial}{\partial x}\left(\overline{u^{2}}\right)-\right.$

$$
\left.\frac{\partial}{\partial y}\left(\overline{u^{\prime} \dot{v}}\right)-\frac{\partial}{\partial z}\left(\overline{u^{\prime} \dot{w}}\right)\right)
$$

- Momentum equation in y-direction

$\left(\bar{u} \frac{\partial \bar{v}}{\partial x}+\bar{v} \frac{\partial \bar{v}}{\partial y}+\bar{w} \frac{\partial \bar{v}}{\partial z}\right)=-\frac{1}{\rho} \frac{\partial P}{\partial y}+v \nabla^{2} \bar{v}+\left(-\frac{\partial}{\partial y}\left(\overline{\hat{v}^{2}}\right)-\right.$

$$
\left.\frac{\partial}{\partial x}\left(\overline{u^{\prime} \dot{v}}\right)-\frac{\partial}{\partial z}\left(\overline{v^{\prime} \dot{w}}\right)\right)
$$

- Momentum equation in z-direction

$\left(\bar{u} \frac{\partial \bar{w}}{\partial x}+\bar{v} \frac{\partial \bar{w}}{\partial y}+\bar{w} \frac{\partial \bar{w}}{\partial z}\right)=-\frac{1}{\rho} \frac{\partial P}{\partial z}+v \nabla^{2} \bar{w}+\left(-\frac{\partial}{\partial z}\left(\overline{w^{2}}\right)-\right.$

$$
\left.\frac{\partial}{\partial x}\left(\overline{u^{\prime} \dot{w}}\right)-\frac{\partial}{\partial y}\left(\overline{v^{\prime} \dot{w}}\right)\right)
$$

In the present work, the following assumptions were taken for simulation:

1. The walls of the casing were assumed to be smooth hence any disturbances in flow due to roughness of the surface were neglected.

2. The friction coefficients for all surfaces were set to, hence friction between the walls and fluid was neglected.

3. Steady state conditions, incompressible fluid flow, turbulent flow and Newtonian fluid.

4. Three dimensional flow simulations.

Geometrical discretization of the centrifugal blower is made for the numeric treatment, and computational grid is generated using FLUENT preprocessor Gambit. There are mainly two types of approaches in volume meshing, structured and unstructured meshing. In structured mesh, the governing equations are transformed into the curvilinear coordinate system aligned with the surface. However; it becomes extremely inefficient and consumes time for complex geometries. Therefore, it has been excluded in this research. In the unstructured approach, the integral form of governing equations is discretized and either a finite-volume or finite-element scheme is used. Unstructured grids are in general successful for complex geometries, so it was used in present work. Figure (8), shows the mesh of centrifugal blower. The final point in a good mesh is the total number of cells generated. It is vital to have enough number of cells for a good resolution but memory requirements increase as the number of cells increase. In this study the average number of mesh are (3400000 cells).

A control-volume based technique that consists of the following steps is used for solution [10]:

1. For velocity, pressure, and conserved scalars, algebraic sets of equations are constructed by the integration of the governing equations on each control volume.

2. Discretized equations are linearized and solved iteratively.

The modeled boundary conditions are those considered with more physical meaning for turbomachinary flow simulations, that is, total pressure at the domain inlet and static pressure proportional to the kinetic energy at the domain outlet [11]. The flow rate is changed by modifying the pressure at the outlet condition, which simulates the closure of a valve. Turbulence is simulated with SST, $\mathcal{K}-\omega$ 
model. The semi-implicit method pressure link equation (SIMPLE) algorithm, second order, upwind discretization have been used to perform the solution of flow inside the blower.

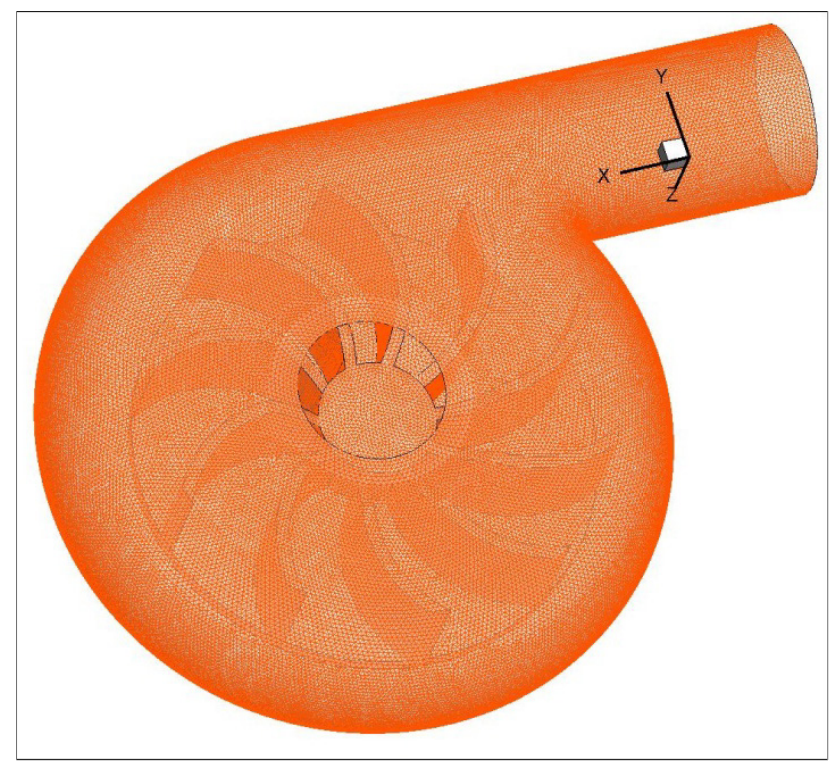

Figure 8. The Mesh of Centrifugal Blower Generated in the Gambit

\section{Results and Discussions}

In this section, we shall discuss the results related to the behavior of the flow in impeller-volute of a centrifugal blower with adding slots. In this work a detailed study and analysis of the rotating stall in term of pressure fluctuations in time and frequency domains has carried out. The experimental were carried out under constant speed (16000 rpm) and variable mass flow rates. The pressure fluctuations take at one point on the casing of centrifugal blower. This point at the exit of impeller $\left(r / r_{i}=1\right)$ and at angular position $60^{\circ}$. Table (2), shows the details of calculations of the mass flow rates. The values were chosen arbitrarily but the maximum values of the mass flow were limited by the control valve design and rotational speed.

Table 2. Details of Final Calculations for Mass Flow Rates.

\begin{tabular}{|c|c|c|c|c|}
\hline$\Delta \mathrm{P}(\mathrm{pas})$ & $\begin{array}{c}\text { Rotational } \\
\text { speed (rpm) }\end{array}$ & $\boldsymbol{R}_{\boldsymbol{e} \boldsymbol{D}} \times \mathbf{1 0}^{\mathbf{3}}$ & $\mathrm{C}$ & $\dot{\mathrm{m}}\left(\boldsymbol{k}_{\boldsymbol{g}} / \boldsymbol{s}\right)$ \\
\hline 0 & 16000 & 0 & 0 & 0 \\
\hline 1970 & 16000 & 18.838 & 0.6070 & 0.01607 \\
\hline 3890 & 16000 & 26.423 & 0.6059 & 0.02254 \\
\hline 5640 & 16000 & 31.792 & 0.6055 & 0.02712 \\
\hline
\end{tabular}

\subsection{Static Pressure Distribution and Overall Performance}

Figures (9) to (12) show static pressure distribution around the impeller (with and without slots) for various mass flow rates. From figure (9), observed increase static pressure at angular position $30^{\circ}$ and decrease the static pressure at angular positions between $60^{\circ}$ and $270^{\circ}$. From figure (10), observed enhancement in pressure distribution with adding slots to the blades comparison with cases withot slots. From figure (11) and (12), observed increase in values of static pressure with adding slots and for all values of static pressure around the impeller.

Figure (13), shows the performance map of the blower. The static and total pressure measurement is taken at outlet of the blower. From the figures, it can be seen that dynamic pressure gradually decreases when mass flow rate decreases. This is due to the fact that, the cross sectional area and density of the flow are constant (i.e. mass flow rate is proportional with flow velocity and dynamic pressure). The figures show also that the total pressure increase with adding slots to the blades this due to increase values of dynamic pressure and increase movement flow between impeller passages.

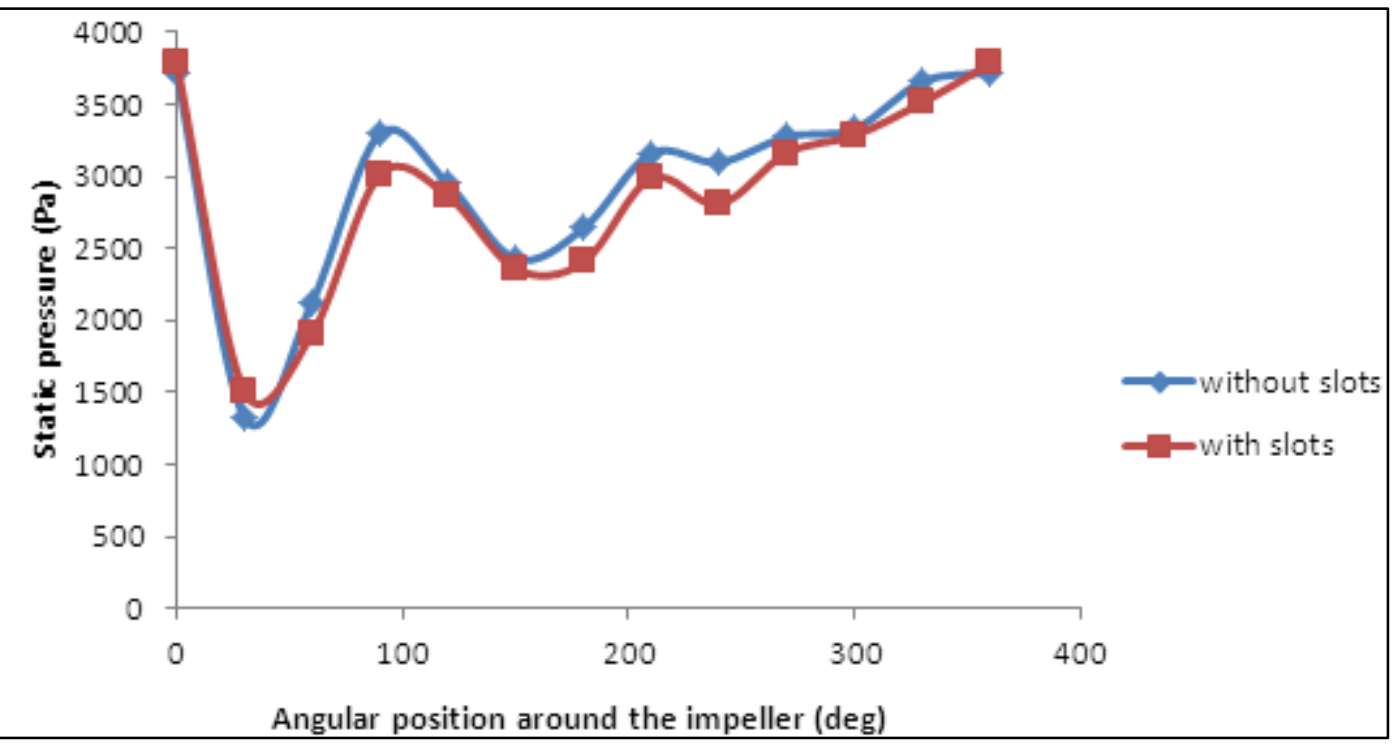

Figure 9. Circumferential Static Pressure Distribution around the Impeller for Mass Flow Rate $0.02712 \mathrm{Kg} / \mathrm{s}$. 


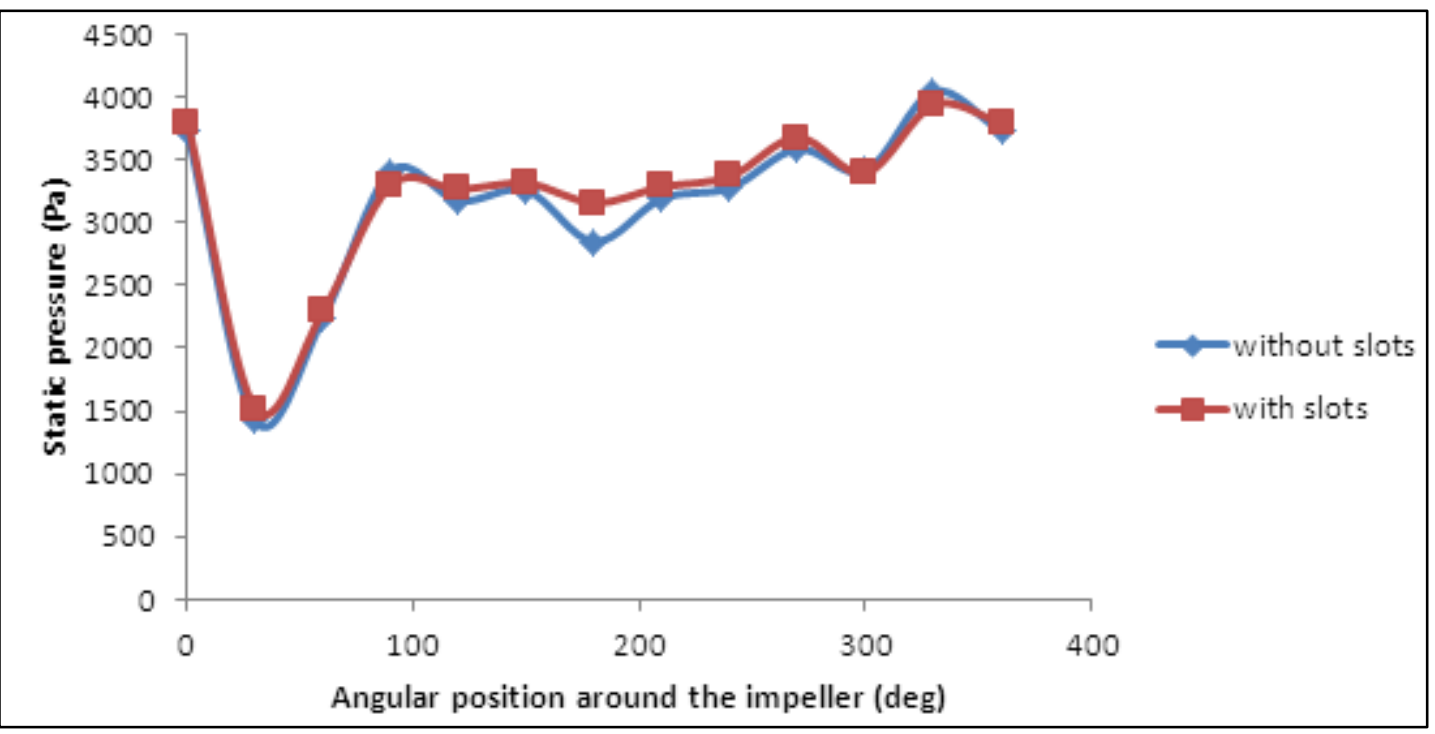

Figure 10. Circumferential Static Pressure Distribution around the Impeller for Mass Flow Rate $0.02254 \mathrm{Kg} / \mathrm{s}$.



Figure 11. Circumferential Static Pressure Distribution around the Impeller for Mass Flow Rate $0.01607 \mathrm{Kg} / \mathrm{s}$.

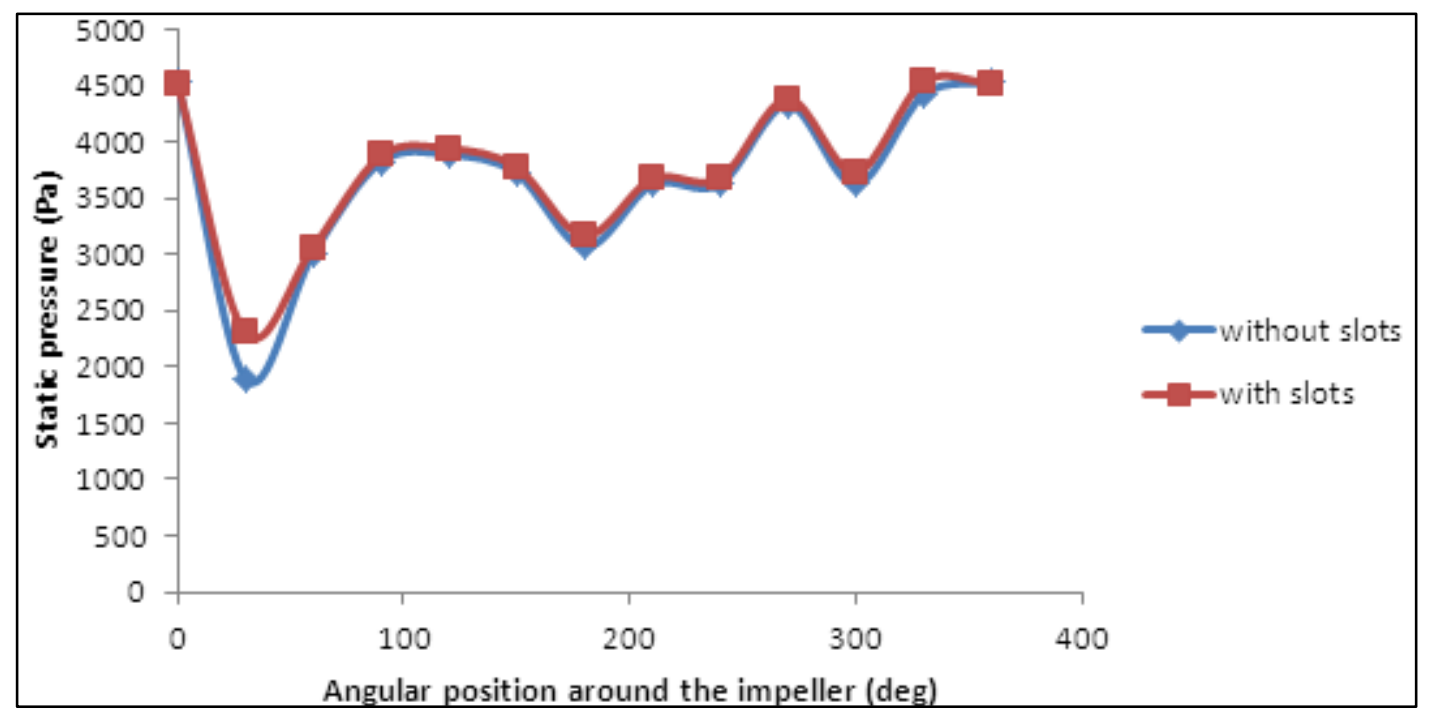

Figure 12. Circumferential Static Pressure Distribution around the Impeller for Mass Flow Rate Equal to Non-Flow. 


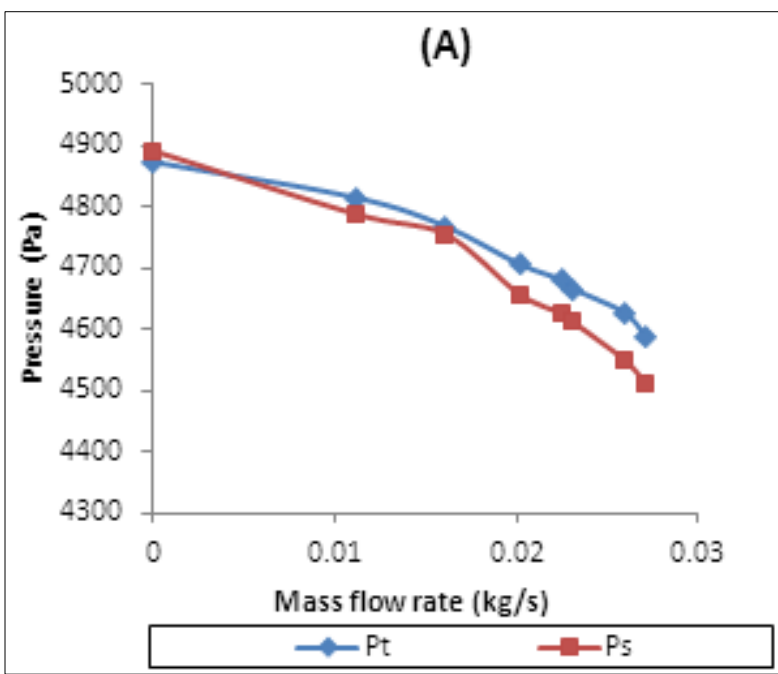

(A) The impeller without slots

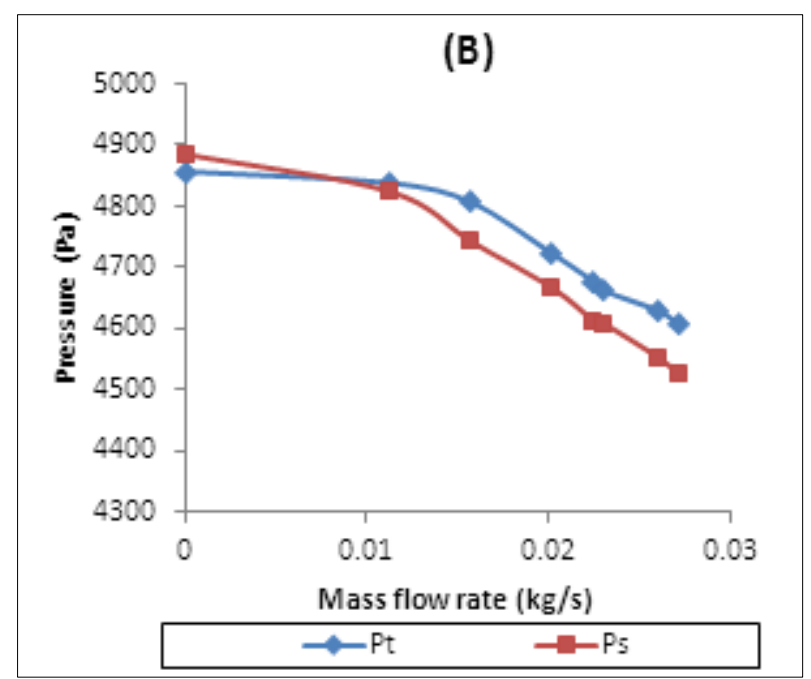

(B) The impeller with slots

Figure 13. Performance Characteristics for Impeller.

\subsection{Time and Frequency Domain Analysis}

Static pressure fluctuations in time domain over a period of 3 second for various mass flow rates at angular position $\varnothing=60^{\circ}$ and at radius ratio $r / r_{i}=1$ around the impeller for three cases are investigated. The figures indicate that pressure fluctuations for various mass flow rates are non-periodical in nature.

Figures (14) and (15) show the pressure fluctuations for various mass flow rates at rotational speed $16000 \mathrm{rpm}$. It is clear from this figure that as the mass flow rate is reduced, the pressure fluctuations amplitude increases. The maximum pressure fluctuations amplitude occurs at mass flow rate equal to nearly non-flow. The figure show also that pressure fluctuations decrease with adding slots to blades. This led to decrease occur of rotating stall phenomenon and increase stability of centrifugal blower.

The power spectrum plots which correspond to the pressure fluctuations for various mass flow rates at angular position $\emptyset=60^{\circ}$ for three cases are represented in Figures (16) and (17). The plot demonstrates the broad band component (from 0 $\mathrm{Hz}$ to $8 \mathrm{~Hz}$ ) which is a manifestation of the higher level of random frequency of pressure fluctuation for various mass flow rates.
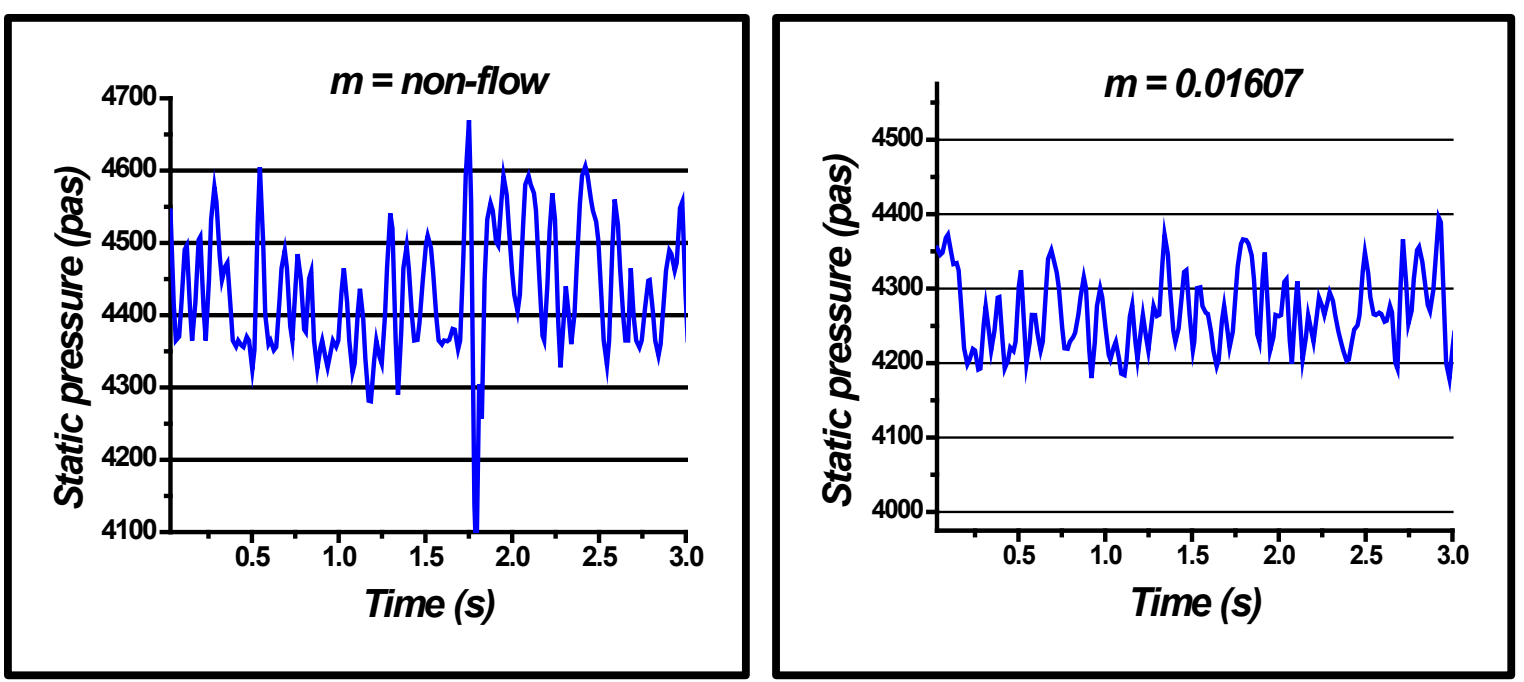

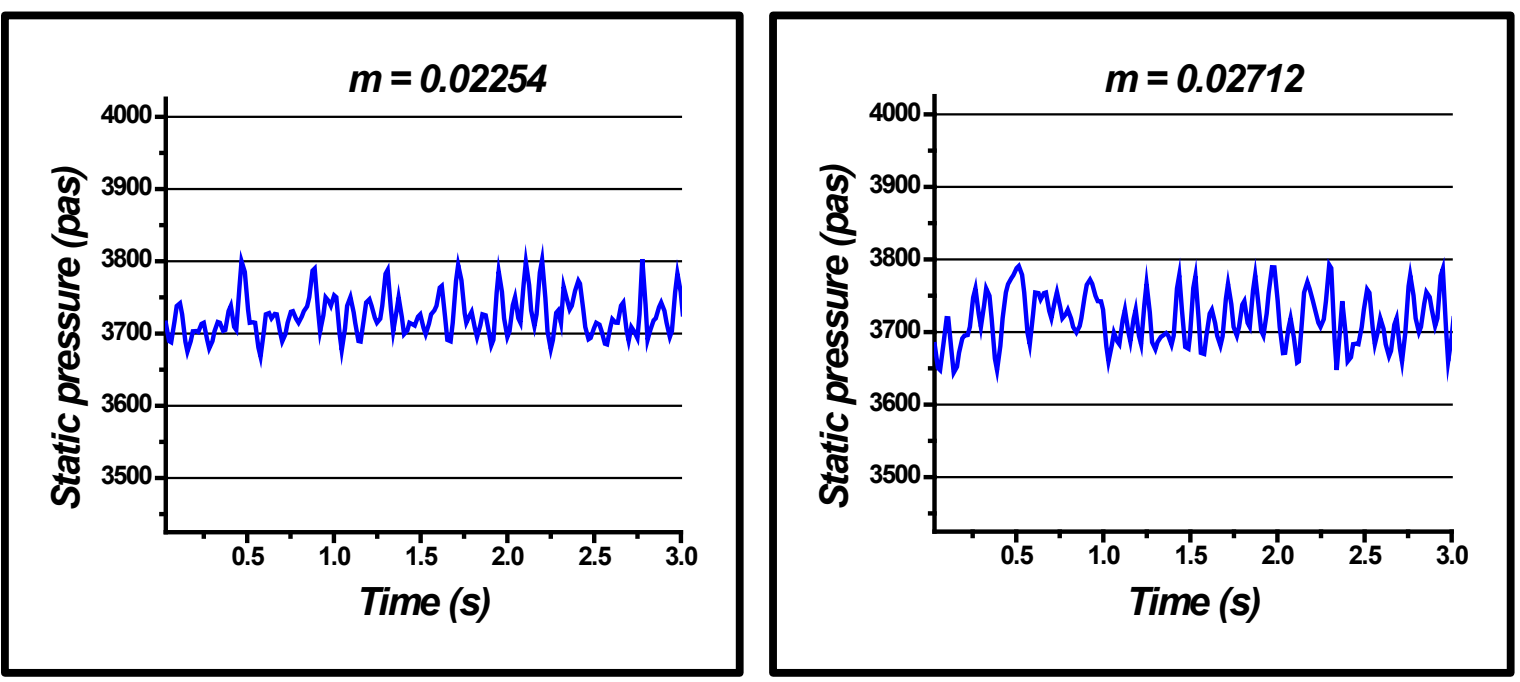

Figure 14. Pressure Fluctuations for Various Values of Mass Flow Rate (kg/s), Without Slots.
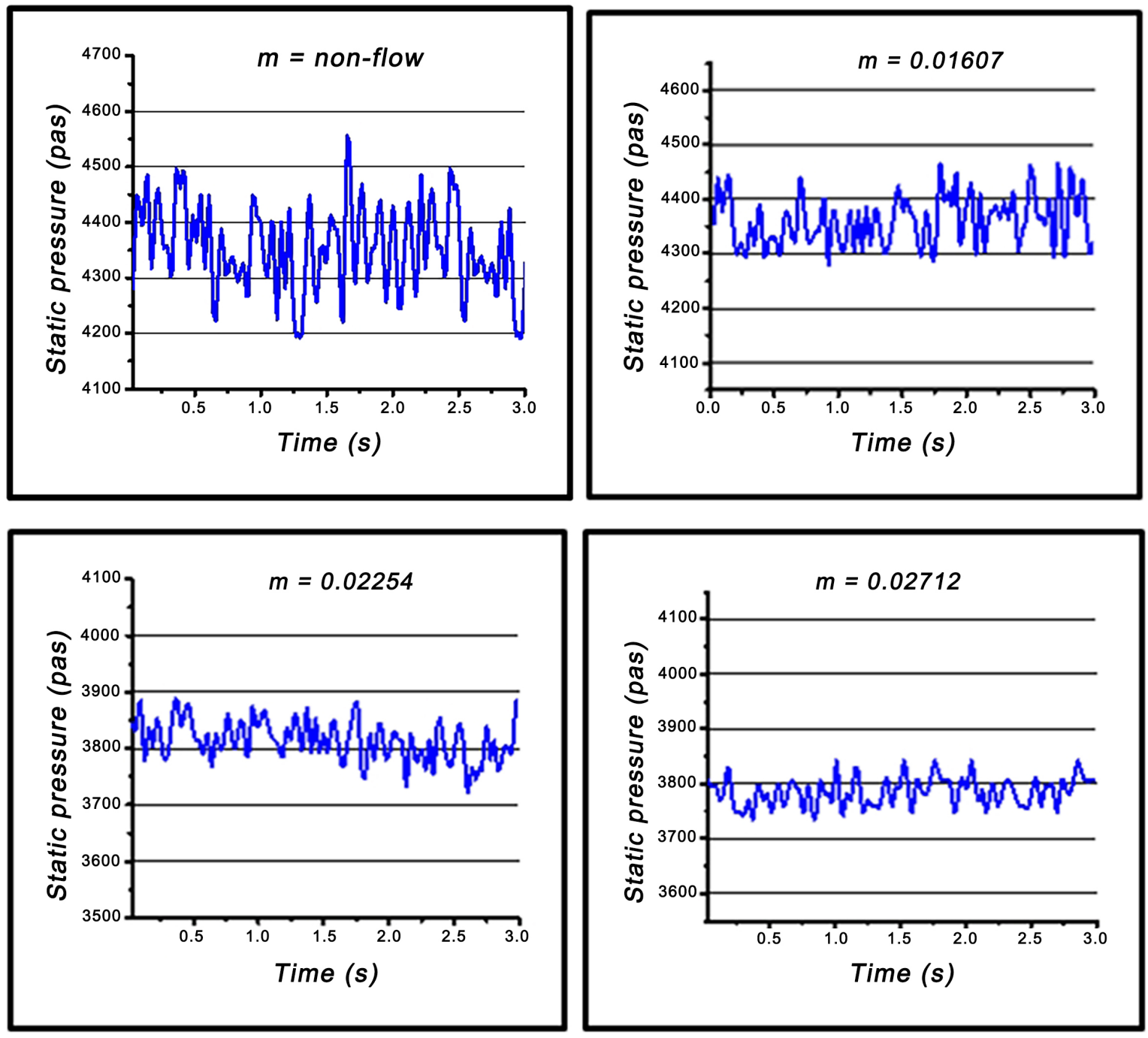

Figure 15. Pressure Fluctuations for Various Values of Mass Flow Rate $(\mathrm{kg} / \mathrm{s})$, With Slots. 

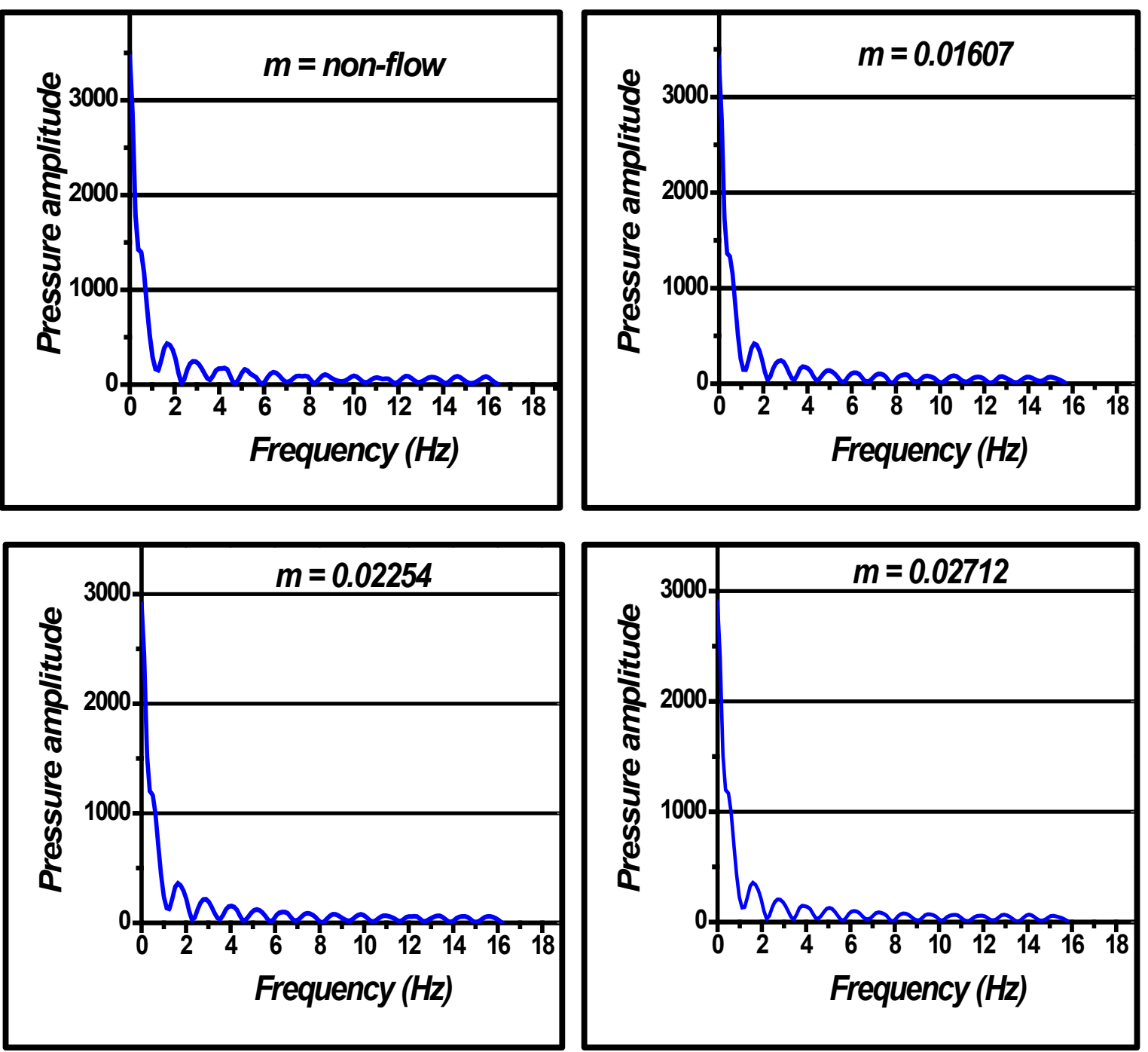

Figure 16. Power Spectrum of Pressure Fluctuations for Various Values of Mass Flow Rate (kg/s), Without Slots.
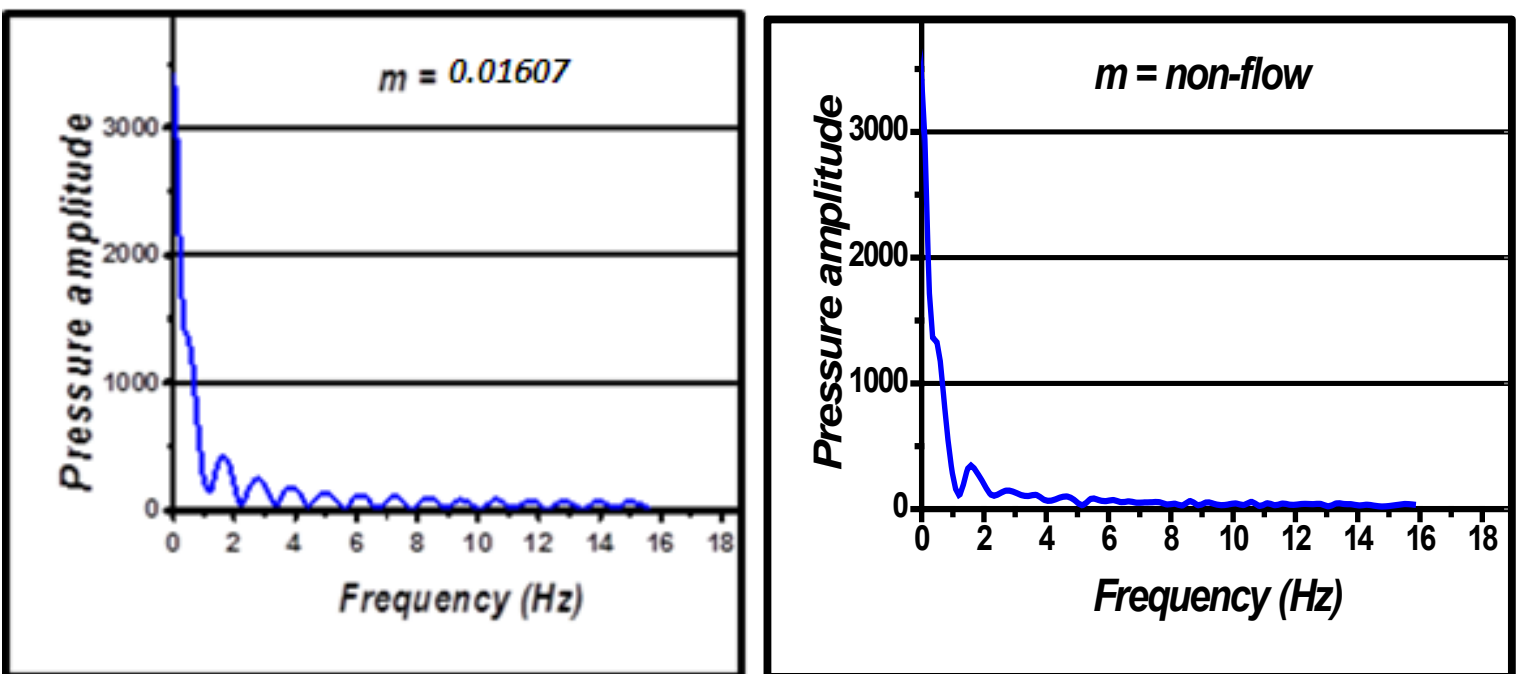

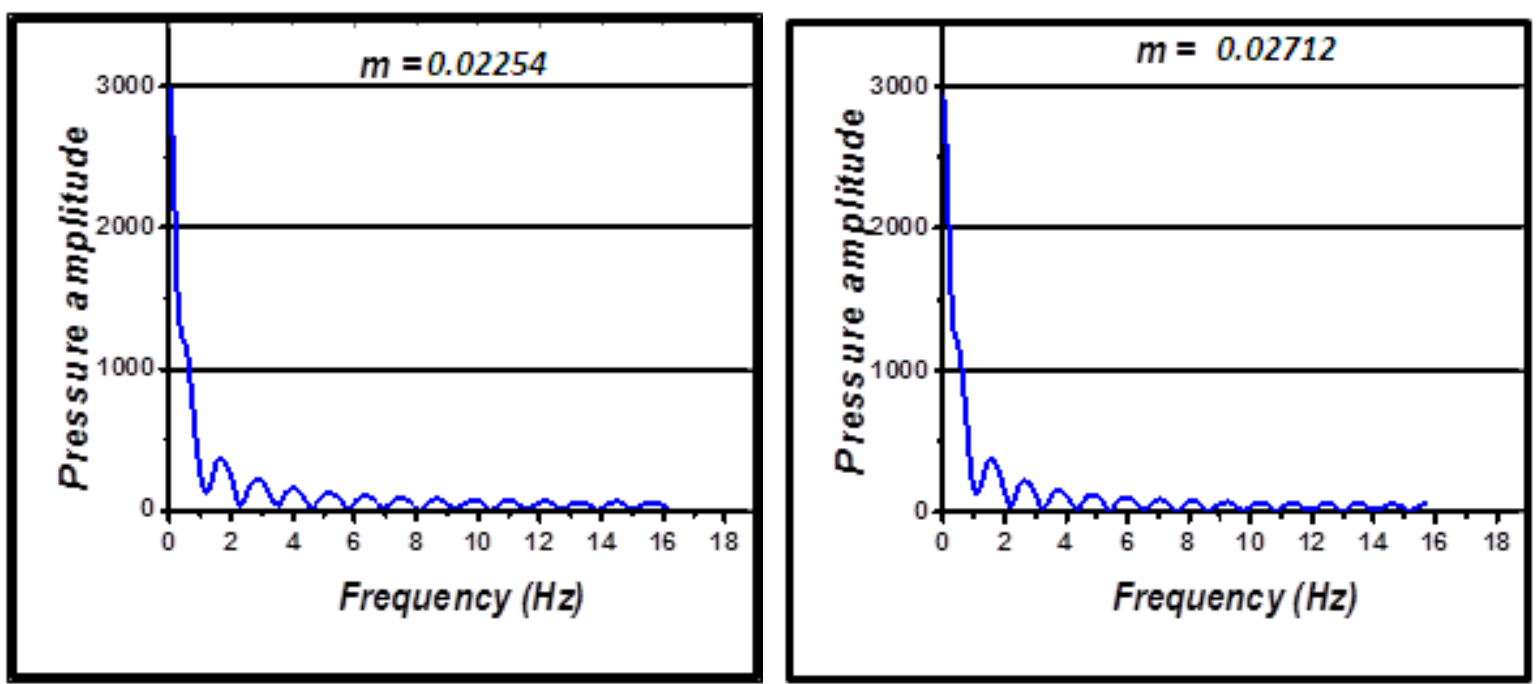

Figure 17. Power Spectrum of Pressure Fluctuations for Various Values of Mass Flow Rate (kg/s), With Slots.

\subsection{Analysis of Numerical Results}

The possibilities of the numerical simulation in the study of the flow inside a blower are wider than the experimental ones. In particular, results corresponding to the pressure distributions inside the impeller and the flow in the volute are presented, and the unsteady calculation combined with the moving reference frame technique has proved to be a good tool to investigate the impeller-volute interaction. All the results take at the plane geometry in z-direction and at distance $21 \mathrm{~mm}$ from the beginning of the blower casing as shown in Figure (18).

Figures (19) to (22) show the static pressure distribution for two cases of impeller (with and without) at various mass flow rates and at rotational speed $(16000 \mathrm{rpm})$. The static pressure rise through the blower is clearly seen in these figures, as are the radial pressure gradients.

The static pressure has a minimum value at the impeller eye, and around the impeller at angular position between $\emptyset=60^{\circ}$ to $180^{\circ}$. We also observed the minimum static pressure at angular position $\emptyset=300^{\circ}$. The static pressure increases between the angular position $\emptyset=0^{\circ}$ to $60^{\circ}$ and angular position $\varnothing=180^{\circ}$ to $\varnothing=270^{\circ}$ around the volute. The recirculation of flow observed from the distance between the tongue and the impeller exit. This lead to increase the static pressure between angular position $\varnothing=0^{\circ}$ to $60^{\circ}$.

The figures show also that the static pressure gradient increase between the angular position $240^{\circ}$ to $300^{\circ}$ with adding slots to the blades.

Agreement between the numerical and experimental data is fairly good and percentage of difference between the experimental and numerical is $12 \%$. Some differences have arisen in the comparison between the numerical and experimental static pressure in the impeller of tested centrifugal blower, especially beyond the tongue region. From this comparison it can be concluded that the increase in static pressure beyond the tongue in the numerical simulation is due to the recirculation of flow in the region between the tongue and impeller exit.

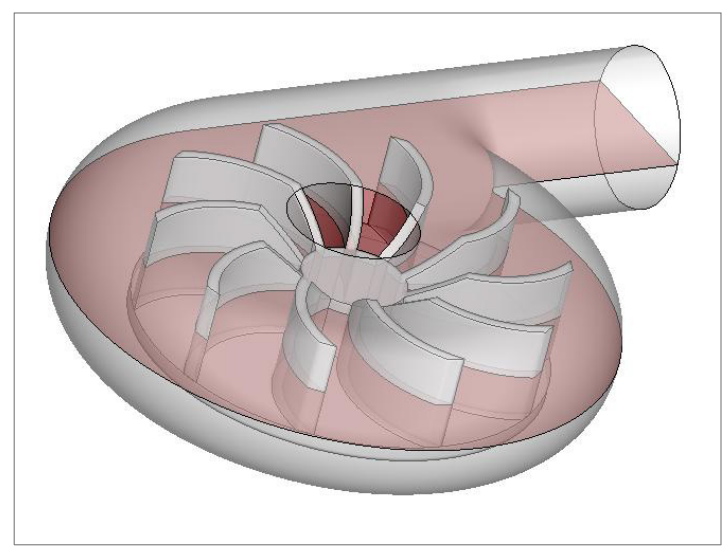

Figure 18. plane geometry at $\mathrm{z}=21 \mathrm{~mm}$

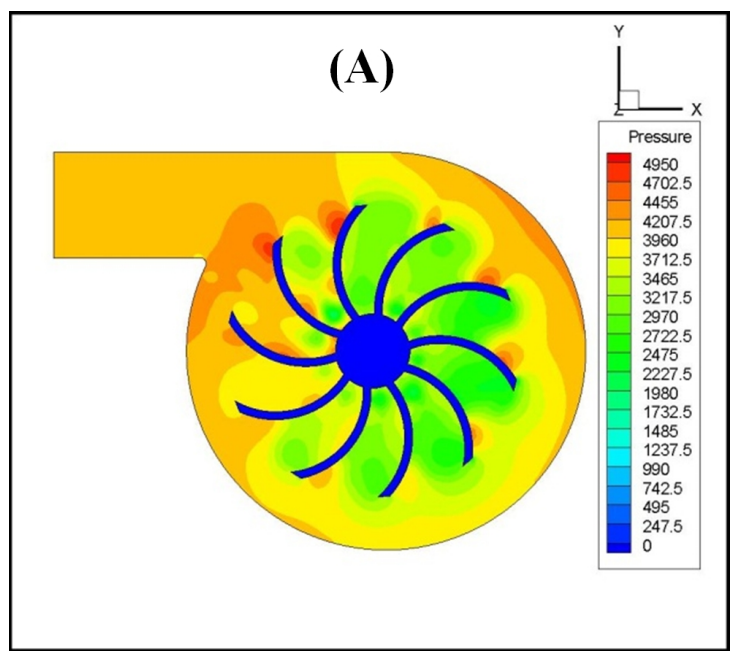

(A) The impeller without slots 


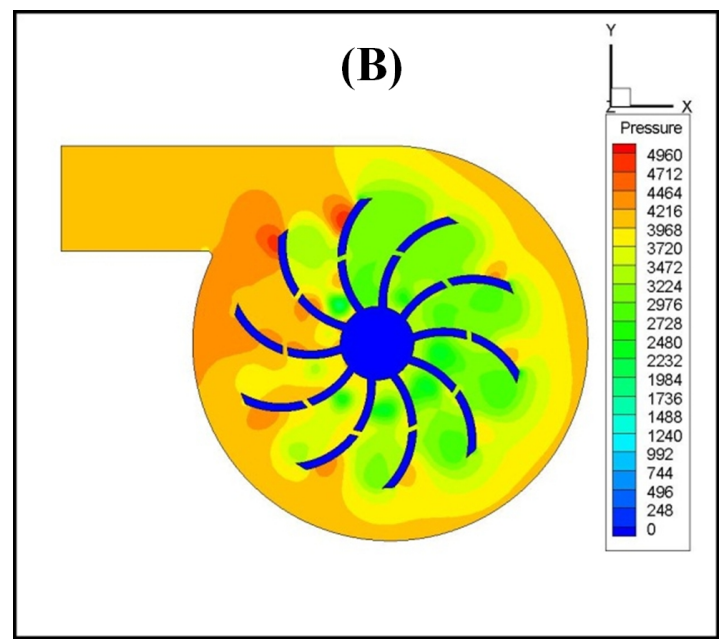

(B) The impeller with slots

Figure 19. Contours of Static Pressure for Two Cases (With and Without Slots) and at Mass Flow Rate Equal to Non-Flow.

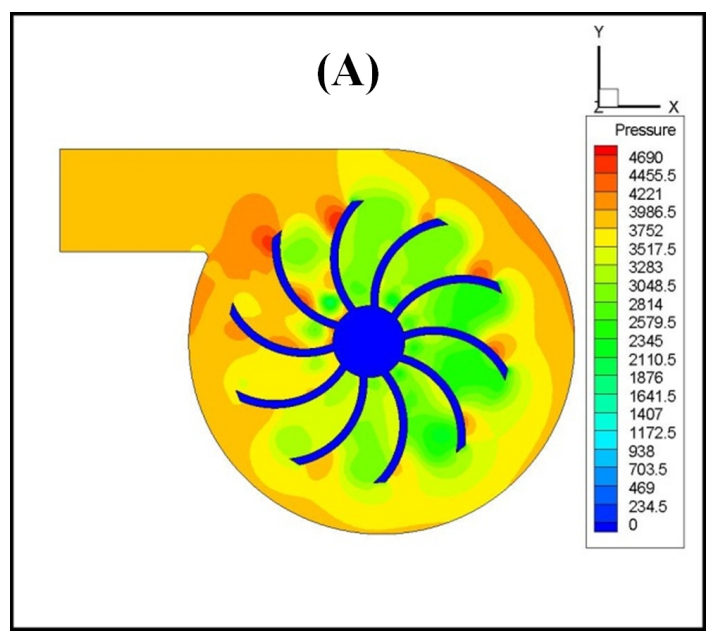

(A)The impeller without slots

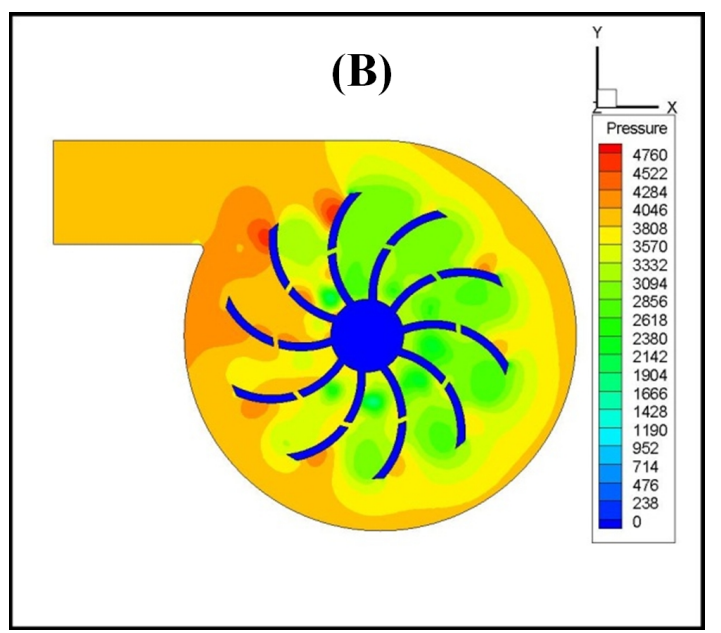

(B) The impeller with slots

Figure 20. Contours of Static Pressure for Two Cases (With and Without Slots) and at Mass Flow Rate $0.01607 \mathrm{Kg} / \mathrm{s}$.

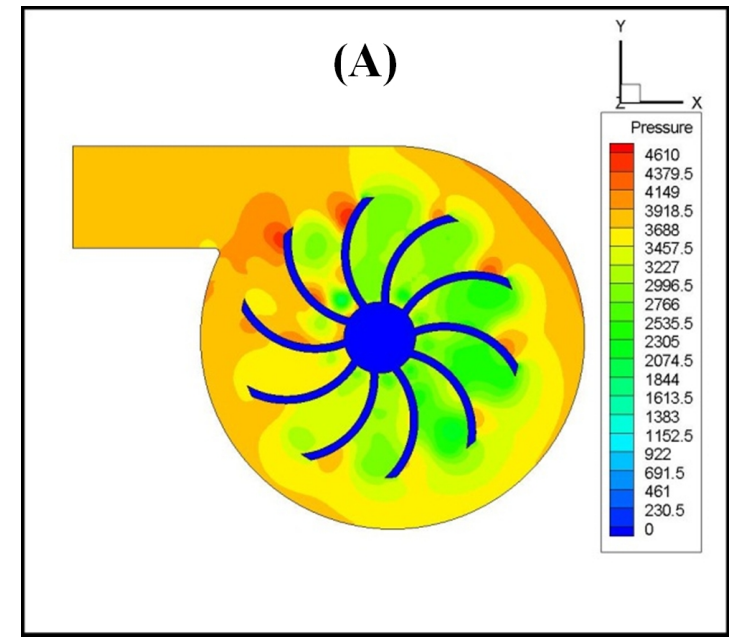

(A) The impeller without slots

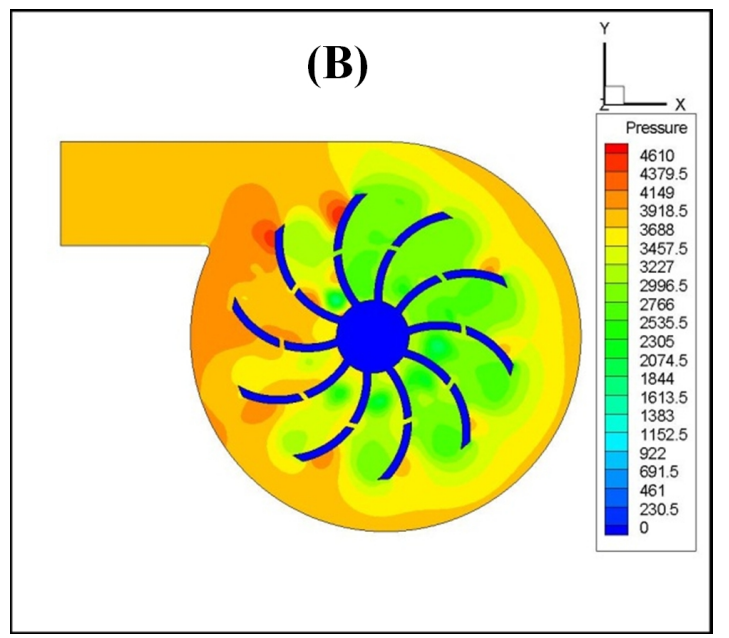

(B) The impeller with slots

Figure 21. Contours of Static Pressure for Two Cases (With and Without Slots) and at Mass Flow $0.02254 \mathrm{Kg} / \mathrm{s}$.

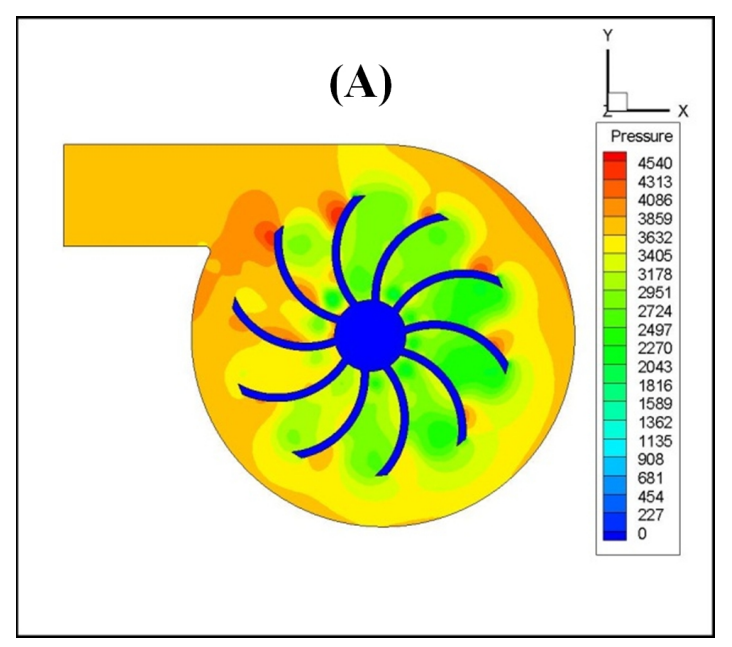

(A) The impeller without slots 


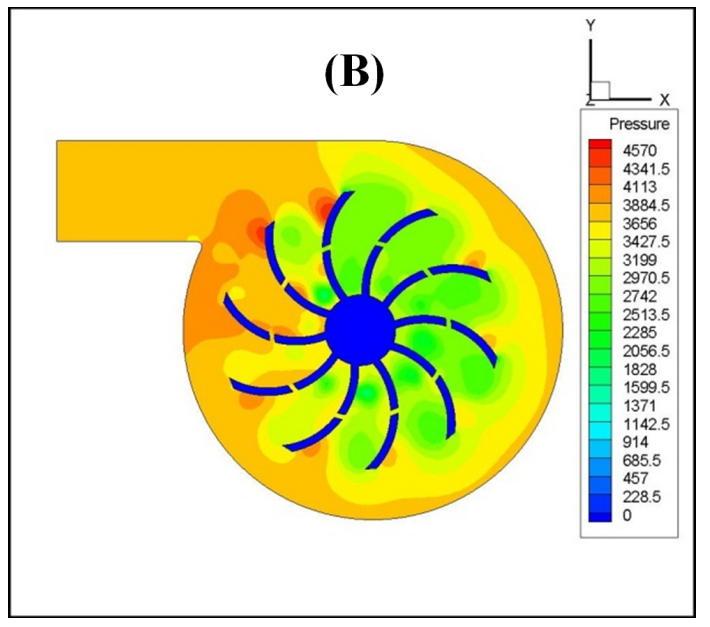

(B) The impeller with slots

Figure 22. Contours of Static Pressure for Two Cases (With and Without Slots) and at Mass Flow Rate $0.02712 \mathrm{Kg} / \mathrm{s}$.

\section{Conclusions}

In general, boundary layer suction slots provided on impeller blades at judiciously chosen locations tend to improve the performance of the centrifugal blower, in terms of static pressure fluctuations. The above experimental and numerical analysis has also established this aspect and more specifically is able to reveal the following inferences.

1. The static pressure increase at angular position $30^{\circ}$ and decrease at angular positions between $60^{\circ}$ and $270^{\circ}$ with adding slots to each blade at mass flow rate equal to $0.02712 \mathrm{~kg} / \mathrm{s}$.

2. Enhancement in pressure distribution with adding slots to the blades comparison with cases withot slots at values of mass flow rate between non-flow and $0.02254 \mathrm{~kg} / \mathrm{s}$.

3. The total and static pressure increase with adding slots to the blades this due to increase values of dynamic pressure and increase movement flow between impeller passages.

4. The pressure fluctuations increase with decrease values of mass flow rates. The maximum pressure fluctuations amplitude occurs at mass flow rate equal to nearly non-flow. We concluded also that pressure fluctuations decrease with adding slots to blades. This led to decrease occur of rotating stall phenomenon and increase stability of centrifugal blower.

5. Agreement between the numerical and experimental data is fairly good and percentage of difference between the experimental and numerical is $12 \%$.

\section{Recommendations}

For future works, the following is recommended:
1. Investigating the effect of adding slots to the impeller blades with various geometries and various widths on rotating stall in blower.

2. Study the effect of adding two slots to each blade on rotating stall phenomenon.

3. Using sliding mesh technique in a finite commercial code to investigate the impeller-volute interaction and comparing it with that of the experimental work are important.

$\begin{array}{ll}\text { Nomenclature } & \\ \mathrm{D} & \text { Impeller exit diameter }(\mathrm{m}) \\ \mathrm{d} & \text { Impeller inlet diameter }(\mathrm{m}) \\ \mathrm{Z} & \text { Number of blade } \\ \beta & \text { Blade angle (deg) } \\ \Delta P & \text { Pressure difference (pascal) } \\ \mathrm{r} & \text { Radius }(\mathrm{m}) \\ \dot{m} & \text { Mass flow rate }(\mathrm{kg} / \mathrm{s}) \\ \mathrm{C} & \text { Discharge coefficient } \\ \mathrm{Re} & \text { Reynolds number } \\ \varnothing & \text { Circumferential angle }(\mathrm{deg}) \\ \mathrm{SST} & \text { Shear stress transform } \\ \mathrm{u}, \mathrm{v}, \mathrm{w} & \text { Velocity component }(\mathrm{m} / \mathrm{s})\end{array}$

\section{REFERENCES}

[1] Nicolas Courtiade, "Experimental Analysis of The Unsteady Flow and Instabilities in a High-Speed Multistage Compressor", Thesis, 2012.

[2] Jan T. Gravdahl, "Modeling and Control of Surge and Rotating Stall in Compressors", Thesis, Department of Engineering Cybernetics, Norwegian University of Science and Technology, 1998.

[3] A.S. Hassan "Influence of the volute design parameters on the performance of a centrifugal compressor of an aircraft turbocharger", IMechE, Vol. 221 Part A: J. Power and Energy, 2007.

[4] S. Sivagnanasundaram, S. Spence and J. Early, "Investigation of Compressor Map width Enhancement and The Inducer Flow Field Using a Shroud Bleed Slot", School of Mechanical and Aerospace Eng. Queen's University Belfast, UK, 2010.

[5] Xiao-Qing Quiang, Ming-Miu Zhu and Jin-Fang Teng, "Effect of Circumferential Grooves Casing Treatment on Tip Leakage Flow and Loss in A Transonic Mixed-Flow Compressor", Journal of Theoretical and Applied M ECHANICS, 51, 4, PP. 903-913, Warsaw 2013.

[6] K. Vasudeva and N. Yagnesh Sharma," CFD Analysis of a Centrifugal Fan for Performance Enhancement Using Converging Boundary Layer Suction Slots", World Academy of Science, Engineering and Technology, 2009.

[7] Raghunathan S. and Cooper R. K.," Passive Boundary Layer Control with Slots in Short Diffuser", ASME Journal of Fluids Engineering, 3, Vol.122, pp.177-179, 2000. 
[8] Wursthorn, S. and Schnerr G. H.," Numerical Investigations of Cavitation Control in Pumps", Journal of Applied Mathematics and Mechanics, Vol.80, pp.S663-S664, 2000.

[9] Laras Davidson, "An Introduction to Turbulence Models", Department of Thermo and Fluid Dynamics, Chalmers University of Technology, Sweden, 2009.
[10] Versteeg H. K., Malalasekera W., "An Introduction to Computational Fluid Dynamic, The Finite Volume", Longman Group Limited, 1995.

[11] Yonas Teshome, "CFD Study on The Performance of Regenerative Flow Pump (RFP) with Aerodynamic Blade Geometry", Thesis, Addis Ababa University, 2007. 